\title{
Grammatical Positions of Focuser Like Among Native English-Speaking Undergraduate Students
}

\author{
Basim Alamri \\ English Language Institute, King Abdulaziz University \\ Jeddah, Saudi Arabia \\ E-mail: bmalamri@kau.edu.sa
}

Received: October 21, 2020 Accepted: December 3, 2020 Published: December 7, 2020

doi:10.5296/ijl.v12i6.17968

URL: https://doi.org/10.5296/ijl.v12i6.17968

\begin{abstract}
Discourse markers (DMs) are used in everyday conversations to serve different meanings and functions. The present exploratory study investigated grammatical positions of focuser like among 60 undergraduate native-English-speaking students at a midwestern university in the United States. Students were asked to read and place focuser like in this sentence: "We have to read five chapters for the final exam". Then students were required to indicate a degree of acceptability of the placement of like at every possible position in sentences that contained the discourse marker like in 10 different grammatical positions. The results showed that students preferred inserting the DM like before a noun phrase, at the beginning of a sentence, and before a verb phrase, respectively. In terms of gender, females frequently posited focuser like before a sentence, whereas males placed it before a noun phrase. Also, the discourse marker like does not occur within auxiliary. Finally, this study draws conclusions about different grammatical positions and broader usages of discourse marker focuser like among younger students.
\end{abstract}

Keywords: Discourse markers, Focuser Like, Grammatical positions

\section{Introduction}

In any daily conversations, some people, especially younger adults, tend to insert words or phrases that may serve different functions, such as like, you know, um, ah (Dailey-O'Cain, 2000). This is called Discourse Markers (DMs), where they are rarely found in prepared or rehearsed speeches, but rarely absent in conversations (Fox Tree \& Schrock, 1999). Discourse marker is defined by Fraser (1999) as "a class of lexical expressions drawn primarily from a class of conjunctions, adverbs and prepositional phrases and with certain 
exceptions they signal a relationship between the interpretations of the segment they introduce S1 and the prior segment S2." (p. 932). Schiffrin (2012) defines DMs as "sequentially dependent elements which bracket units of talk" (p. 31), in which they provide contextual coordinates for utterances.

The discourse marker like is considered as ungrammatical particle. However, it serves different functions in the conversation. Underhill (1987) divided the use of word like in sentences into two parts: grammatical or standard and ungrammatical or nonstandard like. As for the former, it basically means that the word like has a meaning such as in 'I like the concert last week'. Whereas the latter, like is meaningless but it has a function as in 'I was like angry'. Underhill argues that the discourse marker like is 'role governed'. That is, it has different meanings and functions depending on its position in the sentence.

There are different functions for using like in sentences during speaking or uttering conversations. These functions generally are focuser, filler, quotative and approximant. In Underhill's study, he mentioned six syntactic functions for the discourse marker like as follow:

1- Before noun phrase: this is used mostly in the conversations. For example, "Can't you get like a body wave up front?"

2- Before a predicate adjective or adjective phrase as in "The waves were like really big."

3- Before an adverb, adverb phrase, or prepositional phrase functioning adverbially. For example, "Man, get in that car, like now."

4- Before a verb phrase as in "He was like standing right behind me when I said it."

5- Before a subordinate clause as in "People come up and ask me like how does it feel to wrestle."

6- Before the entire sentence as in "It's like the winter sucks in Chicago."

Focuser- and filler-like may share some characteristics which make it sometimes difficult to differentiate between both of them. In general, like can serve as a gap filler when the speaker wants to say or utter something, but the speaker suddenly needs some time to remember or to think of what to say. The speaker usually inserts the word like in order to fill this gap. These discourse or pragmatic markers are considered to be optional rather than required (Dailey-O’Cain, 2000).

On the other hand, quotative-like has a much more specific meaning and a clear grammatical function, as a quotative. The discourse marker quotative-like usually comes after the verb $b e+l i k e$. Ferrera and Bell (1995) stated two common positions for the quotative-like.

1- Before an uttered thought or internal dialogue usually for the first person. For example, when I saw my friend's car, I was like "OMG it is wonderful."

2- Before direct quotation usually for the third person as in 'My brother looked at me and he was like "Get out of my face." 


\section{Mll Macrothink}

International Journal of Linguistics

ISSN 1948-5425

2020, Vol. 12, No. 6

The researchers have been debating whether inserting discourse markers such as like and you know during people speech is a rule-governed (Underhill, 1988) or the discourse markers may occur anywhere in a sentence (Andersen, 2001). Certainly, the reason could be related to the difficulty of defining this debate syntactically. That is, there are no certain rules or even clear judgments that clarify the discussion in literature. Therefore, this paper focused on the discourse marker focuser like.

With regards to focuser like, several research studies have found that it occurs in various syntactic positions in a context (i.e. utterance). For instance, it can occur before a noun phrase, before a preposition, a sentence initially, at the end of a sentence, before or after a verb, or before an adverb and/or adjectives (Meehan, 1991; Romaine \& Lange, 1991; Wolgemuth, 2003). Interestingly, Wolgemuth (2003) found that like never occurred "within well-established compounds, within proverbial expressions" or before a personal pronoun. Schourup (1985) found that focuser like commonly occurred before numerical expressions such as 'He is like 18 years old'. In addition, Dailey-O'Cain (2000) investigated the actual usage and distribution of like in a corpus of informal U.S. English in terms of gender and age. The results found that the oldest age group rarely used focuser like, followed by the middle age group. The youngest age group, however, used focuser like far more frequently among the three groups. Further, the findings showed that males used focuser like slightly more than female. Similarly, D'Arcy (2017) did not find a proportional difference in the use of like as a focus discourse function in terms of gender. However, she argued that men used like more as discourse particle, while women employed like as a discourse marker (Kern, 2020).

In a contrastive corpus-based study, Gabrys (2017) investigated the use of DM like across five different English varieties: the Santa Barbara Corpus of Spoken American English (SBC), British (ICE-GB), Canadian (ICE-CA), Irish (ICE-IR) and New Zealand (ICE-NZ). The results revealed that DM like occurred in utterance-medial position with a focusing function. Also, DM like was used mostly by females in the SBC and males in the ICE-CA.

The present study therefore investigated the grammatical positions of discourse marker focuser-like among undergraduate native-English-speaking students at a midwestern university in the United States. In addition, the study provided common positions and their frequent uses. The social factor was gender. The paper further examined the relationship between males and females in terms of the syntactic positions of focuser-like in a context (i.e. utterances). From the previous research studies, I presumed three hypotheses as follows:

1. Since females stereotypically use like more than males, I suppose that women are more likely to vary grammatical positions of focuser-like than men.

2. The most frequent position for focuser-like is before a noun phrase.

3. The discourse marker focuser-like does not occur within auxiliary. 


\section{Macrothink}

\section{Method}

\subsection{Participant}

The participants in the study were 60 native-English-speaking undergraduate students: 32 students were male and 28 were female. Students were enrolled in composition (I) course in the English department at a U.S. midwestern university.

\subsection{Instruments}

The data was collected through a questionnaire. Students were randomly surveyed by asking them to respond to a five-point Likert scale question, ranging from 'This is a good sentence; I say and hear sentences like this all the time' to 'This is a strange sentence; I wouldn't say it and never heard anything like it'. The sentence used in the present study (i.e., We have to read five chapters for the final exam) was chosen from undergraduate students' daily conversation. Students had to indicate a degree of acceptability of the placement of like at every possible position in sentences that contained the discourse marker like in 10 different positions. These positions were derived from previous studies as well as proposed by the author. The positions were: (1) before an auxiliary verb (_Aux V), (2) before a preposition phrase (__PP), (3) before an adjective phrase (_ Adj), (4) within an auxiliary verb (Within Aux), (5) at the beginning of a sentence (_S), (6) before a noun phrase (_NP), (7) at the end of a sentence $\left(\mathrm{S}_{-}\right),(8)$ after a preposition (Prep _ $)$, (9) before a verb phrase (_VP), and (10) before a noun $(\ldots \mathrm{N})$. The questionnaire was administered at the end of individual class periods with the help of classroom instructors. The questionnaire is presented in Appendix A. The grammatical positions of like (highlighted) were not shown to students. All responses remained anonymous and confidential.

\subsection{Data Analysis}

The data were analyzed through using the SPSS software to find out the results. An independent sample $t$-test was applied to obtain statistical differences between male and female participants in terms of syntactic positions of focuser-like. The data were also analyzed to determine the relationship and differences among the independent variables, including gender. The results were related to the hypotheses and the previous studies.

\section{Results and Discussion}

The overall results of the syntactic positions of focuser-like are shown in Figure 1. The scale of the mean score was ranged from 1 to 5 . A higher mean score referred to that the sentence that is not said, heard or a bad sentence. In contrast, a lower mean was a better sentence (i.e. students might say or hear the sentence). In addition, students who selected number 3 in the scale were not sure whether the sentence is probably good or bad. 


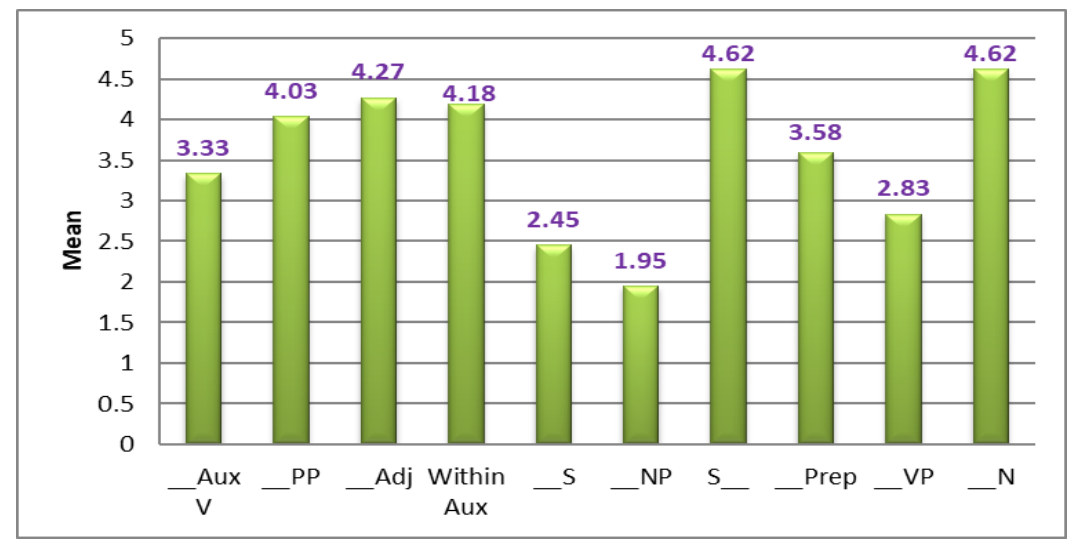

Figure 1. Overall results syntactic positions of focuser-like

As shown in Figure 1, students preferred inserting the DM like before a noun phrase which had the lowest mean $(m=1.95, S D=1.30)$. Also, the second common position was at the beginning of a sentence $(m=2.45, S D=1.25)$. Similarly, the third position was before a verb phrase which the mean score reached $(m=2.83, S D=1.43)$.

On the other hand, students reported that the focuser-like rarely occurred at the end of a sentence or before a single noun in which the mean scores were both the highest $(m=4.62)$. Other positions were reported as unsure or did not know whether they were previously spoken or heard. These positions were before an auxiliary verb $(m=3.33, S D=1.88)$ and before a preposition phase $(m=3.58, S D=1.20)$. Furthermore, putting focuser-like before an adjective was not a good sentence based on the results $(m=4.27, S D=1.02)$. Surprisingly, a few students stated that they said or heard the DM like within an auxiliary verb $(n=6)$ which may indicate that this case is not common in spoken English.

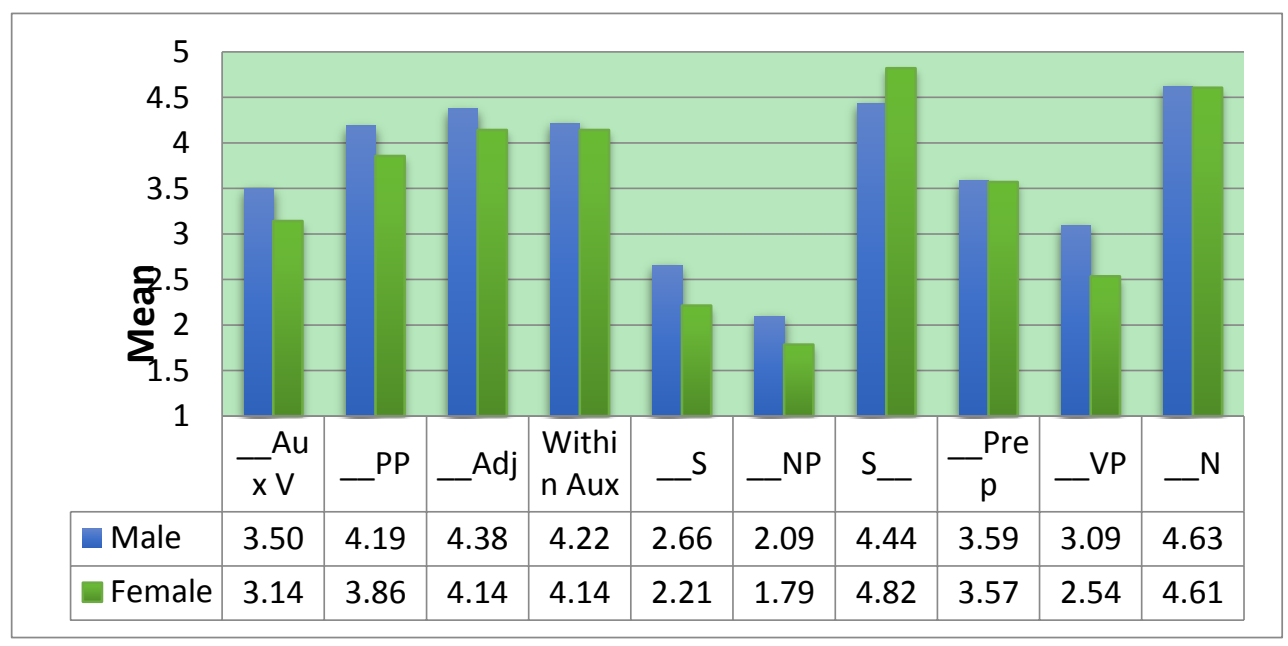

Figure 2. Overall results syntactic positions of focuser-like

In relation to gender, Figure 2 shows the results based on male and female scores. The most frequently positions used by females were before a sentence $(m=2.21, S D=1.17)$, before a verb phrase $(m=2.54, S D=1.37)$ and before a noun phrase $(m=1.79, S D=1.20)$, respectively. Similarly, males shared these positions: before a noun phrase $(m=2.09, S D=1.40)$, a sentence 
initially $(m=2.66, S D=1.31)$. However, the male mean was higher regarding 'before a verb phrase' position $(m=3.09, S D=1.45)$.

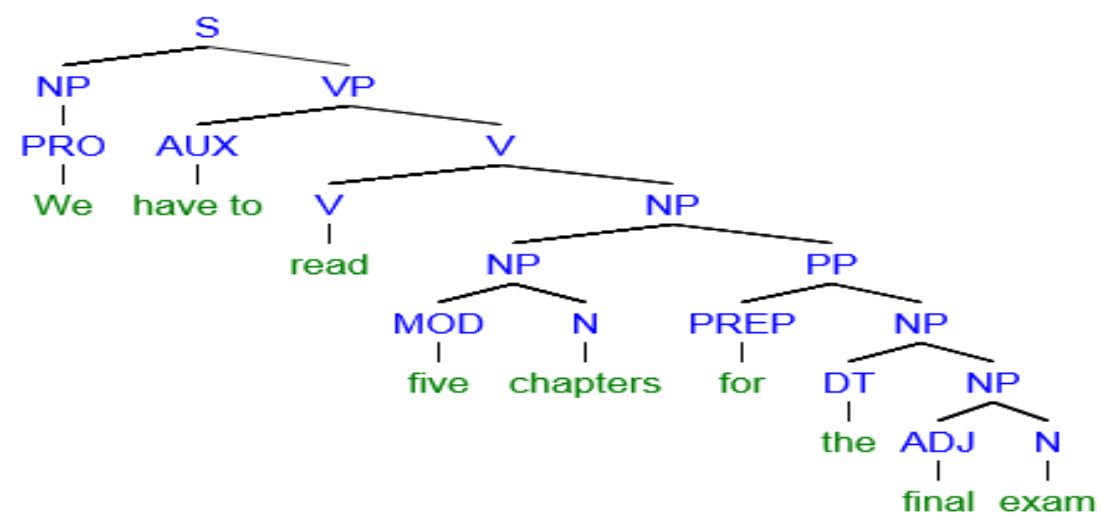

Figure 3. Syntactic tree for the sentence used in the questionnaire

In the following section, the results are discussed and linked to the three hypotheses and previous studies. The syntactic tree for the sentence used in the questionnaire 'we have to read five chapters for the final exam' is presented in Figure 3.

\subsection{Hypothesis 1: Women Vary Using Like in Different Grammatical Positions More Than Men}

As mentioned earlier, women stereotypically speak more Standard English than men. Consequently, women perhaps use focuser-like in many different positions. As shown in Figure 2, it is obvious that females put like in different positions more than males: before a verb phrase, before a noun phrase, and at the beginning of a sentence. When the independent $t$-test was applied to ascertain the significant differences between male and female participants in terms of these positions, the results showed no statistically significant differences. Even though there were slightly differences among the means of some positions (i.e. _ $S$, _ NP, _ VP) when it came to gender, the standard deviations for all positions were very narrow. Table 1 presents the results of differences in focuser-Like positions between males and females. Interestingly, males reported that they were not sure whether it was a good sentence or not regarding inserting like before a verb, whereas females results revealed that it was probably a good sentence. The results in the present study are partially in agreement with the ones in Dailey - O'Cain (2000), in that she did not report any significant differences between men and women. However, Dailey - O'Cain reported that men used focuser like slightly more women.

Table 1. Differences in Like positions between males and females

\begin{tabular}{lllllll}
\hline \multirow{2}{*}{ Like Position } & \multicolumn{2}{l}{ Male $(n=32)$} & \multicolumn{2}{l}{ Female $(n=28)$} & $d f(58)$ & \\
\cline { 2 - 7 } & $\boldsymbol{M}$ & $\boldsymbol{S D}$ & $\boldsymbol{M}$ & $\boldsymbol{S D}$ & $\boldsymbol{t}$ & $\boldsymbol{p}$-value \\
\hline Aux V & 3.50 & 1.83 & 3.14 & 1.96 & .730 & .468 \\
\hline $\mathbf{P P}$ & 4.19 & 1.09 & 3.86 & 1.11 & 1.16 & .251 \\
\hline $\mathbf{\text { Adj }}$ & 4.38 & .976 & 4.14 & 1.08 & .875 & .385 \\
\hline
\end{tabular}




\begin{tabular}{lllllll}
\hline Within Aux & 4.22 & 1.01 & 4.14 & 1.21 & .265 & .792 \\
\hline $\mathbf{S}$ & 2.66 & 1.31 & 2.21 & 1.17 & 1.37 & .175 \\
\hline $\mathbf{N P}$ & 2.09 & 1.40 & 1.79 & 1.20 & .909 & .367 \\
\hline $\mathbf{S} \_$ & 4.44 & 1.16 & 4.82 & .390 & -1.67 & .101 \\
\hline Prep & 3.59 & 1.19 & 3.57 & 1.23 & .671 & .943 \\
\hline $\mathbf{V P}$ & 3.09 & 1.45 & 2.54 & 1.37 & .153 & 1.32 \\
\hline $\mathbf{N}$ & 4.63 & .793 & 4.61 & .875 & .083 & .934 \\
\hline
\end{tabular}

Note. $M$ : Mean, $S D$ : Standard Deviation, $t$ : t-test, $p>.05$

3.2 Hypothesis 2: The Most Frequent Position for the Focuser-Like Is Before a Noun Phrase $(N P)$

The results indicated that the most frequently occurring position of focuser-like is before a noun phrase $(m=1.95)$, followed by a sentence initially $(m=2.45)$. The third position was before a verb phrase $(m=2.83)$. These findings supported a number of previous studies (Andersen, 2001; Wolgemuth, 2003) and contradicted with others (Romaine \& Lange, 1991; Underhill, 1988). Anderson (2001) and Wolgemuth (2003) found that inserting like before a noun phrase was the most common position. However, Romaine and Lange (1991) revealed that a sentence initial position was the most frequently one. Further, Underhill (1988) claimed that focuser-like before a verb phrase was commonly occurred.

\subsection{Hypothesis 3: The Discourse Marker Like Does Not Occur Within Auxiliary}

The majority of students reported that inserting focuser-like within an auxiliary verb was not a good sentence $(m=4.18)$. Unfortunately, the literature lacks previous investigations that discussed placing like within the auxiliary verb, which merits future exploration. Therefore, the present investigation confirms the hypothesis that focuser-like does not occur before auxiliary verb. However, the results showed that only four students rated this position as a good sentence. The possible interpretation could be linked to the study that ascertained the discourse marker like can occur in any position in a sentence (Andersen, 2001).

\section{Conclusion}

This study investigated how native-English speakers undergraduate students posited focuser like in different grammatical positions. The results of the study confirmed two hypotheses and rejected one. To start with the first hypothesis, because there was not a clear-cut statistical gender difference regarding the frequently uses of focuser-like in various grammatical positions; the first hypothesis is not confirmed. Moreover, it is obvious that the second hypothesis is confirmed because the position of discourse marker like before a noun phrase had the highest mean $(m=1.79)$ among other positions. Last hypothesis, despite the few number of students who rated the position of like within an auxiliary verb as a good sentence, the majority reported this sentence as strange and bad. Therefore, this hypothesis is confirmed.

Future research on focuser like needs to investigate more closely aspects of social and regional variation in its use. Since the present study did not focus on the effect of inserting focuser like in daily conversation on the degree of comprehension, future studies would 
examine whether this kind of insertion affects listeners comprehension. Furthermore, the participants in this study were native-English speakers' undergraduate students, future investigations could include international students from different cultural backgrounds.

\section{Acknowledgments}

Special thanks go to the instructors in the English department at the midwestern university for their assistance in collecting data for this study.

\section{References}

Andersen, G. (2001). Pragmatic markers and sociolinguistic variation: A relevance-theoretic approach to the language of adolescents. John Benjamins Publishing Company. https://doi.org/10.1075/pbns.84

D'Arcy, A. (2017). Discourse-pragmatic variation in context: Eight hundred years of like. John Benjamins Publishing Company. https://doi.org/10.1075/slcs. 187

Dailey - O'Cain, J. (2000). The sociolinguistic distribution of and attitudes toward focuser like and quotative like. Journal of Sociolinguistics, 4(1), 60-80. https://doi.org/10.1111/1467-9481.00103

Ferrara, K., \& Bell, B. (1995). Sociolinguistic variation and discourse function of constructed dialogue introducers: the case of be + like. American Speech, 70(3), 265. https://doi.org/10.2307/455900

Fox Tree, J. E., \& Schrock, J. C. (1999). Discourse markers in spontaneous speech: oh what a difference an oh makes. Journal of Memory and Language, 40(2), 280-295. https://doi.org/10.1006/jmla.1998.2613

Fraser, B. (1999). What are discourse markers?. Journal of Pragmatics, 31(7), 931-952. https://doi.org/10.1016/S0378-2166(98)00101-5

Gabrys, M. (2017). Like as a discourse marker in different varieties of English: A contrastive corpus-based study. Retrieved from http://hdl.handle.net/2078.1/thesis:11925

Kern, J. (2020). Like in English and como, como que, and like in Spanish in the speech of Southern Arizona bilinguals. International Journal of Bilingualism, 24(2), 184-207. https://doi.org/10.1177/1367006919826329

Meehan, T. (1991). It's Like, "What's Happening in the Evolution of Like?": A Theory of Grammaticalization. Kansas Working Papers in Linguistics. https://doi.org/10.17161/KWPL.1808.423

Romaine, S., \& Lange, D. (1991). The use of like as a marker of reported speech and thought: a case of grammaticalization in progress. American Speech, 66(3), 227. https://doi.org/10.2307/455799

Schiffrin, D. (2012). Discourse markers. Cambridge University Press.

Schourup, L. C. (1985). Common discourse particles in English conversation. Garland. 
Underhill, R. (1988). Like Is, like, Focus. American Speech, 63(3), 234. https://doi.org/10.2307/454820

Wolgemuth, T. (2003). It's like discourse 'like': The story of 'like' in Canadian English in 1995. Unpublished MA Thesis, University of Toronto.

\section{Appendix A}

\section{Instructions}

The purpose of this questionnaire is to know what you think about the use of "like" in the following sentences.

The 'correctness' of these sentences DOESN'T MATTER and even what your High School English teacher might think about them

Please use this scale to rate your responses:

$1=$ This is a good sentence; I say and hear sentences like this all the time.

$2=$ This is probably a good sentence.

$3=$ I'm not sure if this is OK or not.

$4=$ This is probably not a good sentence.

$5=$ This is a strange sentence; I wouldn't say it and never heard anything like it.

To what extent do you usually say or hear the following sentences:

\begin{tabular}{|c|c|c|c|}
\hline 1 & We like have to read five chapters for the final exam. _ AuxV & ( & ) \\
\hline 2 & We have to read five chapters like for the final exam.__PP & ( & ) \\
\hline 3 & We have to read five chapters for the like final exam. _ Adj & ( & ) \\
\hline 4 & We have like to read five chapters for the final exam. Within Aux & ( & ) \\
\hline 5 & Like we have to read five chapters for the final exam. $\ldots \mathrm{S}$ & ( & ) \\
\hline 6 & We have to read like five chapters for the final exam. _ NP & ( & ) \\
\hline 7 & We have to read five chapters for the final exam like. $\mathrm{S}_{-}$ & ( & ) \\
\hline 8 & We have to read five chapters for like the final exam. Prep _ & ( & ) \\
\hline 9 & We have to like read five chapters for the final exam. __VP & ( & ) \\
\hline 10 & We have to read five chapters for the final like exam. _ $\mathrm{N}$ & ( & ) \\
\hline Ge & Ider: $\quad \square$ Male $\quad \square$ Female & & \\
\hline
\end{tabular}

\section{Copyrights}

Copyright for this article is retained by the author(s), with first publication rights granted to the journal.

This is an open-access article distributed under the terms and conditions of the Creative Commons Attribution license (http://creativecommons.org/licenses/by/4.0/) 